\title{
Carnets
}

Revue électronique d'études françaises de l'APEF

Première Série - 1 Numéro Spécial | 2009

Cultures littéraires : nouvelles performances \& développement

\section{Do encontro da literatura com a medicina}

\section{Margarida Reffóios}

\section{(2) OpenEdition \\ Journals}

\section{Edição electrónica}

URL: http://journals.openedition.org/carnets/4263

DOI: $10.4000 /$ carnets.4263

ISSN: 1646-7698

Editora

APEF

\section{Edição impressa}

Data de publição: 1 Junho 2009

Paginação: 389-398

\section{Refêrencia eletrónica}

Margarida Reffóios, « Do encontro da literatura com a medicina », Carnets [Online], Première Série - 1 Numéro Spécial | 2009, posto online no dia 16 junho 2018, consultado o 30 abril 2019. URL : http:// journals.openedition.org/carnets/4263; DOI : 10.4000/carnets.4263

\section{(c) (1) \&}

Carnets est mis à disposition selon les termes de la licence Creative Commons - Atribution - Pas d'utilisation commerciale 4.0 International. 


\title{
DO ENCONTRO DA LITERATURA COM A MEDICINA
}

MARGARIDA REFFÓIOS

Universidade de Évora

mgsr@uevora.pt

\section{Resumo}

Partindo de exemplos retirados da Literatura Francesa, tentaremos analisar, à luz da Medicina, as doenças associadas à mulher medieval.

Faremos, assim, uma viagem pela História da Medicina, mostrando como esta Ciência do Saber se dilui tão harmoniosamente no texto literário.

Em suma, é nosso desejo provar a especificidade e a eficácia de aspectos de uma cultura comum que beneficia, no contexto actual, a multidisciplinaridade entre as diferentes artes, tão comum já no século XII.

\begin{abstract}
Having as a starting point examples taken from the French Literature we aim at analysing, at the light of Medicine, the diseases associated to the medieval woman.

We will, thus, embark on a journey through the history of Medicine, showing how this Science of Knowledge is harmoniously combined in the literary text.

To conclude, it is our desire to prove the specificity and the effectiveness of aspects of a common culture which, in the current context, benefits the multidisciplinary among different arts, already common in the 12th Century.
\end{abstract}

Palavras-chave: Literatura Francesa Medieval, História da Medicina, Multidisciplinaridade Keywords: Medieval French Literature, History of Medicine, Multidisciplinary 
Je ne crois pas aux choses mais aux relations entre les choses.

Georges Braques

\section{Introdução}

É nosso desejo provar a especificidade e a eficácia de aspectos de uma cultura comum que beneficia, no contexto actual, a multidisciplinaridade entre as diferentes artes, tão comum já no século XII.

\section{O Romance e o quotidiano}

No século XII desenvolve-se a classe cavaleiresca e em paralelo uma literatura em língua vernácula destinada aos laicos que não sabem o latim. Essa literatura inspira-se nas lendas guerreiras e cristãs dos primórdios da sociedade medieval sugerida pelas cantigas de gesta, mas também nas traduções em francês dos textos da Antiguidade latina. É nestas condições que nasce o género romanesco. (Zumthor, 1978).

Segundo Erich Auerbach (Auerbach, 1968), o objectivo central do romance é representar os costumes e os ideais da cavalaria feudal embora as formas exteriores não sejam negligenciadas. Por diversas vezes, a narrativa abandona o cenário longínquo dos contos de fadas para introduzir quadros muito concretos dos hábitos da época. Assim, no romance medieval é posto em primeiro plano um quotidiano que reflecte uma realidade da época, definindo também imagens de um imaginário médico. Produto de uma "consciência particular", a obra literária abre um espaço para a divulgação de outras artes que nela se diluem.

Tomemos como ponto de partida a figura de Thessala (Cligés de Chrétien de Troyes) que representa, na literatura medieval, a imagem da aia que acompanha a sua dama e que exercendo uma grande influência sobre a sua senhora, é também um ser à parte por ter acesso ao mundo do maravilhoso. Thessala apresenta alguns traços de médica embora esteja mais próxima do perfil de curandeira, o saber popular e oral estando na base desse comportamento. De qualquer forma, parece ter "mezinhas" para os males comuns e "poções" para os males de amor. Trata diabetes, gota, anginas, asma e outras infecções vulgares ao mesmo tempo que diz ser melhor que Medeia (a perita em magia). Esta associação é o espelho de uma época assombrada por feitiços e encantamentos:

Je sai bien garir d'itropique, ( açucares)

Si sai garir de l'arcetique, (gota) 
De quinancie et de cuerpous ;(anginas / asma)

Tant sai d'orines et de pous

Que ja mar avroiz autre mire ;

Et sai, si je l'osoie dire,

D'anchantemanz et de charaies (sortilégios)

Bien esprovees et veraies

Plus c'onques Medea n'an sot,

N'onques mes n'an vos dire mot,

Si vos ai jusque ci norrie.

(Chrétien de Troyes, 1982a: 91)

Já no Conte du Graal de Chrétien de Troyes o médico que reduz a luxação de uma das articulações de Keu é acompanhado por duas assistentes que desempenham funções de enfermeiras:

\author{
Li envoie un mire molt sage \\ Et deus puceles de s'escole \\ Qui li raloent sa canole \\ Et si li ont le bras liié \\ Et rasoldé l'os esmiié. \\ (Chrétien de Troyes, 1959: 127-128)
}

O modelo sugerido pelas mulheres médicas - que a História da Medicina baptizou de mulieres Salernitanea - também figura em alguns dos textos. Praticavam medicina e, muitas vezes, surgem como desdobramento, como duplo do médico, embora a medicina exercida por elas esteja mais próxima da medicina curativa por aflorar a magia. O saber das irmãs de Guivret, no romance Érec et Énide é disso exemplo:

La demorerent a sejor

Les serors Guivret ambedeus,

Por ce que biax estoit li leus.

An une chanbre delitable,

Loing de noise, et bien essorable,

En a Guivrez Erce mené ;

A lui garir ont molt pené

Ses serors que il an pria.

(Chrétien de Troyes, 1981: 157) 
Ainda neste romance, o nome da fada Morgana vem associado ao campo da Medicina curativa. Artur fica chocado com as feridas que Érec ostenta e oferece-lhe um unguento feito pela sua irmã:

Puis fet aporter un antret

Que Morgue sa suer avoit fet.

(Chrétien de Troyes, 1981:158)

Esta figura feminina lendária volta a ser citada no Chevalier au Lion, como sendo a autoridade máxima na arte de elaborar remédios na medida em que consegue fazer desaparecer qualquer tipo de dor:

Mes tost aler nos an covient,

Car d'un oignement me sovient

Que me dona Morgue la sage ;

Et si me dist que si grant rage

N'est an teste, qu'il ne l'en ost.

(Chrétien de Troyes, 1982b:90)

Poderia, ainda, referir outros nomes como o da mãe de Isolda que fabrica o filtro do amor para que esta se apaixone pelo seu prometido. Imagem interessante a que se cria nesta lenda de Tristão e Isolda pois verifica-se a intenção de forjar a paixão de Isolda e do rei Marco, a união da jovem com o velho (com orelhas de burro) através de um químico.... Alquimia, magia, fármaco, o texto que, só por si, é naïf mostra como existe um fundo real que apoia o imaginário literário, embora com algumas incongruências. Por exemplo, o filtro, numa das versões, é limitado a três anos.

\section{O quotidiano do romance}

Passemos, então, os olhos pela História da Medicina para compreender este quotidiano esboçado no romance. Durante a segunda metade do século XII, grande parte do saber médico é adquirido através de traduções árabo-latinas realizadas na Escola de Salerno, das obras de Constantino, o Africano (c. 1010-1087), e através das traduções vindas da Península lbérica. Na verdade, as duas regiões que determinam a transmissão árabe são o Sul de Itália, com Constantino, o Africano e a cidade de Toledo, em Castela, onde se deu, em meados do século XII, a convergência das três culturas medievais: a católica, a judia e a árabe. 
Foi, de facto, no campo da Medicina que o Ocidente ganhou em primeiro lugar um corpus significativo de textos vindos do árabe. No século $X$ já havia algumas influências no domínio da Astronomia e da Matemática, mas é o projecto de Constantino, no século XI, que representa o grande marco. De qualquer forma, estas traduções do século XI revelaram-se de uma importância fulcral para o Ocidente porque permitiram lançar as bases de uma verdadeira ciência, em língua latina.

É também de notar que toda a Medicina árabe começa por traduzir textos gregos e assimilar textos de diferentes culturas. Só depois do século IX é que se desenvolve uma ciência árabe propriamente dita com a imposição dos enciclopedistas árabes. O apogeu da civilização árabe dá-se no século $X$, três nomes sendo de referência obrigatória: Al-Razi, AlMagusi e Ibn Sina. O primeiro, filósofo, é baptizado pela cultura europeia com o nome de Razes (850-926). Era visto como o Galeno (130-200) dos árabes. O segundo, cujo nome significa "mago", deixou um único livro, O Livro Real ou O Livro completo sobre a arte médica. O último viu o nome latinizado para Avicena (980-1037), viveu na Pérsia, no século $X$, e era considerado um génio pois era extremamente prolífico - diz-se que escrevia cerca de cinquenta páginas por dia. O seu Cânone, onde propõe uma nova codificação do saber médico greco-árabe, foi a base de estudo da Medicina na Europa até ao século XVII e na Índia até ao século $X X$.

Mas a Medicina também se inspirou nos trabalhos chegados pelas vias italiana e espanhola. Em Roma, durante muito tempo, o exercício da Medicina estava a cargo de escravos que, antes de serem capturados, eram médicos. Os homens livres, na sua maioria, eram gregos que vinham para Roma exercer definitiva ou temporariamente. É o caso de Galeno (130-200), no século II. A via espanhola tem como representantes Averróis (11261198), nascido em Córdova e Gerardo de Cremona (1114-1187), próximo de Constantino, o Africano pois a sua missão foi traduzir, na segunda metade do século XII, o maior número de textos possível, embora não se tenha limitado aos textos de Medicina. O facto de ter abarcado todas as áreas fez deste autor um pensador único na Idade Média. Contudo, os frutos do seu trabalho, cujo espírito é puramente enciclopédico, só se farão sentir no século XIII (Tullio, 1975).

Do ponto de vista teórico, a Medicina estava ligada à Filosofia e a outras ciências. Ou seja, quem praticava a Medicina tinha que conhecer a dialéctica e todo o quadrivium. Aliás, o Pantegni, tradução infiel da enciclopédia médica de Ali ibn al-Abbas al-Magusi (finais do século X), incentivava o médico a ultrapassar as barreiras da sua ciência e a aceitar outras influências. A Filosofia e a Teologia surgiam, ainda, no limite das Ciências Médicas pois, muitas vezes, nos tratados a Medicina e a Filosofia confundiam-se.

Os finais do século XI e o século XII serão de uma enorme importância para o novo rumo das Ciências Médicas. É nessa altura que uma Medicina dita científica se impõe, 
deixando de lado todo o percurso que estava ligado à charlatanice. Na realidade, o século XII serve para aprofundar essa ciência que precisava de encontrar definições mais justas. A distinção entre prática e teoria não foi facilmente absorvida na medida em que o ensino médico, do século XII até ao Renascimento, esteve espartilhado por essa tensão. A Medicina no século XII é vista como a ciência da modernidade e segundo Michael Mc Vaugh os textos de cirurgia da Alta Idade Média são mais numerosos do que os da Antiguidade clássica, embora apresentem um carácter compilatório e repetitivo (Mc Vaugh, 1995).

Já no século XIII, começam a aparecer nos textos de Cirurgia relatos de experiências pessoais. Assim, a tradição escrita passa a permitir que o cirurgião faça a sua própria "publicidade". Mas é difícil avaliar a prática exercida e as melhorias técnicas realizadas pelos cirurgiões da Idade Média porque a escrita limita o desenvolvimento de determinados pormenores práticos da cirurgia. Na verdade, os escritos elaborados não são nada mais do que utensílios para usar contra os concorrentes. Assim, surgem relatos textuais imensos de técnicas referidas em obras antigas que, certamente, os cirurgiões nunca terão experimentado.

Há uma barreira entre a teoria e a prática das Ciências Médicas. A teoria é, na realidade, a ciência que permite conhecer as causas da doença enquanto que a prática é a ciência que permite conhecer o modo de combater as discrasias. Este é o preceito anunciado pelo Cânone de Avicena que a Medicina medieval pôs em prática desde o século XII ao dividir as ciências médicas nessas duas partes distintas. É certo que só a teoria traz a certeza por ser racional. Mas os médicos têm consciência de que esta deve ser completada pela experiência, na medida em que cada caso é um caso diferente. O Isagoge lohannitii e o Pantegni também impuseram a subdivisão da Medicina em duas partes, uma prática e outra teórica, divisão esta que já tinha sido introduzida na Alta Idade Média por algumas das traduções greco-latinas de inspiração alexandrina.

O exercício da arte de curar, durante a Idade Média, encontrava-se repartido por três grupos profissionais: os médicos, os cirurgiões e os barbeiros. Só no século XIII é que a Medicina é reconhecida como uma verdadeira profissão, quando as actividades médicas passam a ser regulamentadas. Para além destes três grupos, rivais entre si, há ainda a considerar os representantes dos pequenos ofícios, como as parteiras ou os charlatães que faziam passar, a todo o custo, a sua arte enganadora. Segundo o dicionário de Wickersheimer (Wickersheimer, 1979), a percentagem provável para estes três grupos profissionais seria de $57 \%$ para os médicos, $12,4 \%$ para os cirurgiões e $19,8 \%$ para os barbeiros que se limitavam a praticar a pequena cirurgia do quotidiano, ou seja, tratar ampolas e abcessos, entre outras tarefas simples. 
Os cirurgiões, mais conhecedores da Anatomia, intervinham para reduzir as fracturas ou tratar chagas de origem diversa e faziam ainda intervenções como a extracção de cálculos renais.

A Obstetrícia também já era considerada uma especialidade cirúrgica. Os partos eram praticados numa sala especial aquecida, onde as parturientes dispunham de uma cama. O trabalho de parto era da responsabilidade das parteiras, pois esta profissão era exercida exclusivamente por mulheres. Tirando esta prática, na realidade, o exercício da Medicina era-Ihes vedado pois não era permitido frequentarem a Universidade. Contudo os dados são contraditórios. Nos documentos que aludem à participação feminina na Medicina da época, os que fornecem mais informações provêem do Sul de Itália. É claro que pode haver várias explicações para este fenómeno. Pode acontecer que, por serem numerosas e ser comum a prática da Medicina por elementos femininos, não tenha havido a preocupação, na altura, de referir a sua contribuição em documentos oficiais. Ou então, que tenha havido um maior número de praticantes médicas em determinada região, sem que para isso haja uma explicação coerente. Os contornos são, de facto, obscuros. Por exemplo, em França há notícia de que nos finais do século XIII houve uma tentativa de controlar os barbeiros-cirurgiões a favor dos médicos, por parte da Universidade de Paris. Neste conflito também se viram atacadas as mulheres pois, da mesma forma que não podiam exercer o Direito foi decretado que não podiam exercer a Medicina. A justificação revelou ser de enorme peso pois a Universidade defendia que mais grave do que perder uma causa por erro de acção, era matar uma pessoa. É claro que a questão não se colocava no masculino e a verdade é que há notícia de mulheres médicas que mostraram uma sensibilidade particular no que diz respeito à cura e à elaboração de remédios. Hildegarda de Bingen (1098-1179) é uma dessas mulheres, que se revelou uma pensadora notável, inovadora na arte da Medicina e muito virada para a natureza feminina. Salvatore de Renzi, historiador do Centro Médico de Salerno, no século XIX, pensa que tenha havido inúmeras mulheres mencionadas na literatura médica do século XI e XII, as mulieres Salernitanae, que praticavam Medicina mas também escreviam sobre tratamentos. De entre as médicas referidas, a mais conhecida é Trótula (séc. XII) que se impôs como sábia. Não se sabe se o seu nome é real ou imaginário mas compôs dois tratados sobre a saúde feminina. Estes opúsculos, que tiveram muita aceitação, estão ligados à Escola de Salerno e não devem ser anteriores ao século XI. Um, trata as doenças próprias de mulheres, De passionibus mulierum, vulgarmente conhecido como Trotula Major, o outro dedica-se à maneira de cuidar da pele, dos cabelos, dos dentes, o De ornatu mulierum ou Trotula minor.

A distinção entre médico e cirurgião é institucionalizada a partir do século XIII. O médico é um letrado que procura a sua ciência nos livros e não na observação do doente. $O$ cirurgião é um técnico que, de acordo com o médico, faz sangrias e outras intervenções 
práticas. Na verdade, a profissão do médico tem a ver com as artes ditas liberais e a do cirurgião com as artes mecânicas. É neste contexto que podemos entender como funcionou, a partir do século XIII, o ensino da Medicina. Assiste-se, assim, a uma divisão do meio médico entre universidades e outro tipo de centro de estudos. Na verdade, pouco a pouco, as universidades adquirem o direito exclusivo à formação dos praticantes habilitados a exercer Medicina, sendo a Cirurgia retirada das aulas. Esta exclusão da Cirurgia terá tido provavelmente a ver com a imposição da Igreja que interditava a dissecação de cadáveres.

Pode-se dizer que o ensino universitário era reservado apenas aos futuros médicos, embora se tenha verificado que nem todos se formavam. Com o desenvolvimento da universidade, a Medicina sábia deixa de ser monástica. De facto, o monge médico tinha por obrigação tratar as pessoas que eram acolhidas no interior do convento, mas também se deslocava a casa dos doentes.

Na primeira metade do século XIII, o exercício da Medicina tomará um rumo diferente com a introdução, na sociedade, dos clínicos formados na universidade. No que diz respeito às obras médicas divulgadas, espelho de uma Ciência Médica viva, Danielle Jacquart classifica, por um lado, receitas que aparecem isoladamente (Jacquart, 1981) e por outro lado, as obras catalogadas de acordo com a sua forma e o tema principal. Uma das categorias é composta pelos comentários que estão orientados para os problemas de doutrina médica. A outra, pelas obras que se ocupam da prática e que englobam os Regimes de Saúde, muitas vezes escritos a pedido de um paciente, os Consilia que, pela exposição de diagnósticos e de prescrições terapêuticas para casos particulares, serviam de modelo aos clínicos, e as recolhas que têm, muitas vezes, o título de Experimenta, que referem alguns exemplos de doenças encontradas pelo médico no decorrer da sua prática. As Experimenta eram divididas em dois grupos. Por um lado, incluíam os tratados gerais que encaravam o conjunto dos problemas médicos. É nesta categoria que se podem englobar as enciclopédias de saber médico e as obras de carácter escolástico e pedagógico. Por outro lado, surgiam agrupados os tratados que abordavam um domínio específico da Medicina. A este género pode-se juntar a literatura abundante consagrada à peste, a partir do século XIV. Danielle Jacquart propõe ainda uma última categoria composta pelas obras que oferecem um simples inventário de drogas, sem que haja um desenvolvimento da teoria medicamentosa. Esta autora acrescenta ainda alguns dados interessantes sobre as obras científicas:

La pratique de la médecine allait rarement de pair avec la composition d'ouvrages scientifiques. Les sources les plus explicites sur l'état des connaissances médicales dans les milieux les plus lettrés, en France au 12ème siècle, sont constituées par des œuvres dont les auteurs ne semblent pas avoir été praticiens, comme Eudes de 
Champagne, Raoul de Longo Campo et surtout Guillaume de Conches. L'influence de l'École de Salerne, perceptible chez ces auteurs, principalement dans la Philosophia Mundi de Guillaume de Conches, se manifeste également par la relation de la venue à Cluny du maître Barthélemy et de son disciple Bernard, auprès de l'abbé Pierre Le Vénérable. D'ailleurs, l'enseignement salernitain, joint à celui de l'École de Montpellier, alors naissante, allait permettre dans la seconde moitié du XIlème siècle à deux médecins, nés l'un en lle-de-France, l'autre en Provence, à savoir Gilles de Corbeil et Bernard Provincialis, de composer des oeuvres originales dignes d'avenir. (Jacquart, 1981: 259-261)

Em suma, o século XII fica associado, na História da Medicina, a uma série de textos vindos do Oriente que marcaram a forma de lidar com a doença.

\section{Conclusões}

O perfil do médico que é desenhado nos romances analisados dá conta de uma entidade credível muito influenciada pela medicina oriental e que é chamada a intervir quando a situação clínica de determinada personagem assim o pede. O médico, figura real, é imposto num imaginário criado em torno de um universo literário, tendo apenas uma intervenção pontual (fazendo a ponte entre dois mundos distintos: o da ficção e o da realidade).

Acabaria esta intervenção remetendo para um estudo actual que promove o convívio de artes distintas:

Pour le dire autrement, sans craindre la métaphore: si l'on veut bien admettre en effet que l'art est ce qui permet de faire respirer l'univers de nos représentations collectives en y faisant jaillir l'oxygène du réel, qu'il a dès lors une fonction vitale comparable à celle du rêve dans la vie psychique individuelle, qu'il est en somme le rêve du monde, alors, force est de reconnaître que Gauguin visait juste en disant de la critique qu'elle est non pas la " vigie vigilante " qu'elle devrait être mais «notre censure ", celle qui produit tant qu'elle le peut du refoulement, résolument sourde à l'invention artistique qu'elle renvoie à l'absurdité : tant qu'elle le peut, dans la mesure où la névrose collective lui permet de maintenir, d'endiguer ce réel, ce «maudit » réel toujours mal dit, celui qui, tôt ou tard, dans la vie psychique de l'individu exactement comme dans l'univers forclos des représentations communes, fera violemment retour. (Leclair, 2005, 114-115) 


\section{Bibliografia}

AUERBACH, Erich (1968). "Les aventures du chevalier courtois", Mimésis. La représentation de la réalité dans la littérature occidentale. Paris, :Gallimard, p.140-167.

GREGORY, Tullio. (1975). "La nouvelle idée de nature et de savoir scientifique au XII ème siècle",. In : J.E.Murdoch and E.D.Sylla. The Cultural Context of Medieval Learning. Dordrecht - Holand, p. 202.

JACQUART, Danielle (1981). Le milieu médical en France du XII ème au XV ème siècles, Genève : Librairie Droz

LECLAIR, Bertrand (2005). Verticalités de la Littérature. Pour en finir avec le « jugement » critique, Seyssel : Champs Vallon.

MC VAUGH, Michael (1995). "Stratégies thérapeutiques: la chirurgie". In : Miirko D.Grmek, Histoire de la pensée médicale en Occident. Paris : Éditions du Seuil, p. 243-244.

TROYES, Chrétien de (1959). Le Roman de Perceval ou le Conte du Graal, Paris : Honoré Champion.

TROYES, Chrétien de (1981). Érec et Énide, Paris : Honoré Champion.

TROYES, Chrétien de (1982a). Cligés, Paris : Honoré Champion.

TROYES, Chrétien de (1982b). Le Chevalier au Lion, Paris : Honoré Champion.

WiCKERSHEIMER, E. (1979). Dictionnaire biographique des médecins en France au Moyen Age, Genève.

ZUMTHOR, Paul. (1978) "Genèse et évolution du genre". In : Jean Frappier et Reinhold R.Grimm.

Grundriss der Romanischen Literaturen des Mittelaters : Le Roman jusqu'à la fin du XIIlème siècle. Heidelberg : Carl Winter, p. 60-81. 